Limnol. Oceanogr., 45(1), 2000, 246-250

(C) 2000, by the American Society of Limnology and Oceanography, Inc.

\title{
Calcification does not stimulate photosynthesis in the zooxanthellate scleractinian coral Stylophora pistillata
}

\begin{abstract}
The interaction between photosynthesis and calcification remains poorly known in zooxanthellate scleractinian corals. We tested whether calcification is a significant source of $\mathrm{CO}_{2}$ for photosynthesis in Stylophora pistillata. Rates of net photosynthesis, respiration, and calcification were measured on colonies incubated in synthetic seawater (SSW) controlled with respect to the inorganic carbon system and containing standard $\left(11.40 \mathrm{mmol} \mathrm{\textrm {kg } ^ { - 1 }}\right)$ and low $(2.85 \mathrm{mmol}$ $\mathrm{kg}^{-1}$ ) calcium concentrations. Net photosynthesis and respiration are not significantly different in standard and low-Ca ${ }^{2+}$ SSW despite a rate of calcification 2.0-2.4 times lower in $\mathrm{Ca}^{2+}$-depleted SSW. Additional experiments carried out on the noncalcifying zooxanthellate Anthozoa Anemonia viridis demonstrate that a low calcium concentration has no direct effect on rates of photosynthesis and respiration. It is suggested that calcification is not a significant source of photosynthetic $\mathrm{CO}_{2}$ and that photosynthesis stimulates calcification rather than the opposite.
\end{abstract}

The processes of photosynthesis and calcification display a number of interactions both at the cellular and the organismal levels in zooxanthellate scleractinian corals (reviewed by Gattuso et al. 1999). It is, however, still not known which process supports the other. It has long been thought that photosynthesis stimulates calcification. The basis of this hypothesis is the observation that calcification is higher in the light than in the dark: a recent review of the literature showed that the median ratio of light: dark calcification is 3.0 (Gattuso et al. 1999). A recent report suggested that calcification is dark repressed (Marshall 1996), a conclusion that was subsequently challenged (Carlon 1996; Goreau et al. 1996) and is not supported by previously published data (see Gattuso et al. 1999). Rather, it is generally accepted that calcification is light enhanced during the day (see Barnes and Chalker 1990). One of the mechanisms invoked is that the photosynthetic uptake of $\mathrm{CO}_{2}$ increases the carbonate ion concentration and favors calcium carbonate precipitation (Goreau 1959; Goreau and Goreau 1959):

$$
\begin{array}{cl}
\mathrm{CO}_{2}+\mathrm{H}_{2} \mathrm{O} & \rightarrow \mathrm{CH}_{2} \mathrm{O}+\mathrm{O}_{2} \\
\mathrm{Ca}^{2+}+2 \mathrm{HCO}_{3}^{-} & \rightarrow \mathrm{CaCO}_{3}+\mathrm{CO}_{2}+\mathrm{H}_{2} \mathrm{O} \text { (calcification) }
\end{array}
$$

This mechanism is not consistent with the recent finding that bicarbonate $\left(\mathrm{HCO}_{3}^{-}\right)$, not $\mathrm{CO}_{2}$, is the inorganic carbon species that is actively absorbed by endodermal cells and subsequently dehydrated to $\mathrm{CO}_{2}$ that is used by zooxanthellar photosynthesis (reviewed by Allemand et al. 1998). An alternate model was proposed by Allemand et al. (1998) to explain the stimulation of calcification by photosynthesis. It involves the buffering of the $\mathrm{H}^{+}$ions produced by calcifi- cation (Eq. 3) by the $\mathrm{OH}^{-}$ions liberated by the dehydration of $\mathrm{HCO}_{3}^{-}$(Eq. 4):

$$
\begin{aligned}
\mathrm{HCO}_{3}^{-}+\mathrm{Ca}^{2+} & \rightarrow \mathrm{CaCO}_{3}+\mathrm{H}^{+} \\
\mathrm{HCO}_{3}^{-} & \rightarrow \mathrm{CO}_{2}+\mathrm{OH}^{-} \\
\mathrm{OH}^{-}+\mathrm{H}^{+} & \rightarrow \mathrm{H}_{2} \mathrm{O}
\end{aligned}
$$

Equations 3-5 combine to provide the general equation of $\mathrm{CaCO}_{3}$ precipitation (Eq. 2).

McConnaughey (1991, 1995) and McConnaughey and Whelan (1997) proposed an opposite interaction according to which calcification stimulates photosynthesis. They described a trans-calcification model where the $\mathrm{H}^{+}$ions released by $\mathrm{CaCO}_{3}$ precipitation are removed from the site of calcification by the $\mathrm{Ca}^{2+}$-ATPase that supplies calcium (stoichiometry is $2 \mathrm{H}^{+}$for each $\mathrm{Ca}^{2+}$ ion transported). The $\mathrm{H}^{+}$ ions are liberated in the coelenteron where they are used for $\mathrm{HCO}_{3}^{-}$dehydration to produce $\mathrm{CO}_{2}$ (Eq. 4). According to this model, photosynthesis is stimulated by the increased the availability of $\mathrm{CO}_{2}$ in the coelenteron.

It is well known that calcification decreases as a function of decreasing calcium concentration in seawater (e.g., Tambutté et al. 1996; Gattuso et al. 1998). This response has been previously used to inhibit calcification in low-calcium artificial seawater and measure the rate of photosynthesis. Net photosynthesis of some organisms is lower in low-calcium seawater (reviewed in McConnaughey 1994; Al-Moghrabi et al. 1996), which supports the trans-calcification model. However, several drawbacks in the procedures that were used may have resulted in confounding conclusions. First, it is likely that the inorganic carbon system of the artificial seawater used was not controlled. It is of prime importance that the dissolved inorganic carbon and $\mathrm{CO}_{2}$ partial pressure are identical in the various batches of artificial seawater used. Otherwise, the decrease in photosynthesis observed may be the result of an inhibition by a lower supply of inorganic carbon rather than by a reduced supply of $\mathrm{CO}_{2}$ by calcification. Second, the direct effect of low-calcium concentration on photosynthesis was not investigated. It is therefore possible that the decrease of photosynthesis in low-calcium seawater results from a direct inhibition of $\mathrm{HCO}_{3}^{-}$ transport similar to the one observed in a coccolithophorid (Brownlee et al. 1994). Third, calcium-free artificial seawater was sometimes used (Al-Moghrabi et al. 1996) that probably elicits a wide range of physiological responses as calcium plays numerous roles in cell biology.

The aim of this paper is to assess the validity of one aspect of the trans-calcification model according to which calcification enhances photosynthesis. The rates of net photosynthesis, respiration, and calcification of the zooxanthellate scleractinian coral Stylophora pistillata were measured in artificial seawater controlled with respect to the inorganic 
Table 1. Composition (mol kg-1) of synthetic seawater (SSW); salinity $=38.5$.

\begin{tabular}{lcc}
\hline \hline & $\begin{array}{c}\text { Low calcium } \\
\text { concentration } \\
\left(25 \% \mathrm{Ca}^{2+}\right)\end{array}$ & $\begin{array}{c}\text { Normal calcium } \\
\text { concentration } \\
\left(100 \% \mathrm{Ca}^{2+}\right)\end{array}$ \\
\hline $\mathrm{NaCl}$ & 0.469230 & 0.452136 \\
$\mathrm{CaCl}$ & 0.002849 & 0.011396 \\
$\mathrm{KCl}$ & 0.011231 & 0.011231 \\
$\mathrm{Na}_{2} \mathrm{SO}_{4}$ & 0.031064 & 0.031064 \\
$\mathrm{MgCl}_{2}$ & 0.058113 & 0.058113 \\
$\mathrm{Na}_{2} \mathrm{CO}_{3}$ & 0.002008 & 0.002008 \\
$\mathrm{HCl}$ & 0.001757 & 0.001757 \\
\hline
\end{tabular}

carbon system, displaying normal or low calcium concentrations. Additionally, the effect of low calcium concentration on the rate of net photosynthesis of a noncalcifying zooxanthellate anthozoan was investigated.

Materials and methods-A series of experiments was conducted in the laboratory using six colonies of the branching zooxanthellate scleractinian coral S. pistillata (Esper 1797) and one specimen of the zooxanthellate sea anemone Anemonia viridis (Forskål 1775) collected in the Mediterranean (Villefranche-sur-Mer, France). The coral colonies were propagated from small fragments of parent colonies collected in the Gulf of Aqaba (Jordan). They were suspended, several weeks prior to the experiments, on nylon strings and maintained in a 300-liter aquarium supplied with heated Mediterranean seawater pumped at a depth of $50 \mathrm{~m}$. Each piece of coral displayed approximately the same form and size. The culture conditions for corals were salinity $=38.5$, temperature $=27 \pm 0.5^{\circ} \mathrm{C}$, irradiance $=300 \mu \mathrm{mol}$ photons $\mathrm{m}^{-2} \mathrm{~s}^{-1}$ (metal halide lamp, Philips HPIT $1000 \mathrm{~W}$ ), photoperiod 12:12. The culture conditions for the sea anemone were salinity $=38.5$, temperature $=19 \pm 0.5^{\circ} \mathrm{C}$, light $=$ $125 \mu \mathrm{mol}$ photons $\mathrm{m}^{-2} \mathrm{~s}^{-1}$ (metal halide lamp, Philips HQIT $400 \mathrm{~W})$, photoperiod 12:12.

The experimental sequence was identical for each coral colony: it was taken in the culture aquarium and suspended in a beaker containing $250 \mathrm{ml}$ of normal or low-calcium synthetic seawater (SSW) for a 30-min preincubation at or near saturating irradiance $\left(300 \mu \mathrm{mol}\right.$ photons $\left.\mathrm{m}^{-2} \mathrm{~s}^{-1}\right)$ or in the dark. The colony was then incubated for $1 \mathrm{~h}$ in a perspex chamber containing $240 \mathrm{ml}$ of normal or low-calcium SSW in order to measure the rates of photosynthesis and respiration. The incubation medium was continuously agitated using a magnetic stirrer. Both the preincubation beakers and the respirometry chamber were kept at $27^{\circ} \mathrm{C}$ in a thermostated water bath to maintain the temperature constant. Each colony was first incubated in SSW with normal $\mathrm{Ca}^{2+}$ concentration and in low-Ca ${ }^{2+} \mathrm{SSW}$ on the next day. All incubations took place between 10:00 and 17:00. The colonies were returned to the culture aquarium and their rate of calcification measured a few days later. They were incubated for $2 \mathrm{~h}$ in 200-ml open-top beakers containing standard or low-calcium SSW, under environmental conditions identical to those used for the measurement of photosynthesis and respiration. Incubations took place both in the light and dark.
Table 2. Parameters of the inorganic carbon system of the standard and low-calcium synthetic seawater.

\begin{tabular}{lc}
\hline \hline Total alkalinity $\left(\mu \mathrm{Eq} \mathrm{kg}^{-1}\right)$ & 2,259 \\
Dissolved inorganic carbon $\left(\mu \mathrm{mol} \mathrm{kg}{ }^{-1}\right)$ & 2,008 \\
$\mathrm{pH}$ (NBS) & 8.23 \\
$\mathrm{pH}$ (SWS) & 8.08 \\
$\mathrm{CO}_{2}$ partial pressure $(\mu \mathrm{atm})$ & 360 \\
\hline
\end{tabular}

The incubation medium was filtered on Whatman GF/C membranes and stored at $4{ }^{\circ} \mathrm{C}$ pending analysis of total alkalinity. The colonies were frozen upon completion of the last incubation and kept at $-20^{\circ} \mathrm{C}$ pending protein determination.

The experimental sequence for the sea anemone was slightly different: the specimen was left in the incubation chamber overnight in order to enable its fixation on the chamber wall. The chamber contained seawater filtered on $0.45-\mu \mathrm{m}$ membranes (FSW). The next day, FSW was replaced with normal or low $\mathrm{Ca}^{2+} \mathrm{SSW}$ (incubation in normal SSW took place first). SSW was changed after a 30-min preincubation period, and photosynthesis and respiration were measured, respectively, at saturating irradiance (300 $\mu$ mol photons $\mathrm{m}^{-2} \mathrm{~s}^{-1}$; Bénazet-Tambutté et al. 1996). The sea anemone was frozen at the end of the second incubation and kept at $-20^{\circ} \mathrm{C}$ pending determination of protein.

Oxygen concentration was monitored in the chamber and stored every 1 min using a data-logger (LI-1000, Li-Cor Inc.). Dissolved $\mathrm{O}_{2}$ was measured using a Ponselle polarographic electrode calibrated daily against air-saturated seawater and a saturated solution of sodium sulfite (zero oxygen). Both the standard and low-calcium SSW were very close to saturation with respect to oxygen at the beginning of the incubations (101\%; range: 96-105\%). The maximum change in the dissolved oxygen concentration was $12.3 \%$ in the light and $-15.7 \%$ in the dark. The rates of net photosynthesis and respiration were estimated using a linear regression of $\mathrm{O}_{2}$ against time. The rates of calcification were estimated from the changes in total alkalinity (TA) during the course of the incubation using the alkalinity anomaly technique (Smith and Key 1975). TA was measured potentiometrically, using an automated titrator (DL70, Mettler), as described by Gattuso et al. (1993). The titrations took place within 2-3 d of sampling. The rates of net photosynthesis, respiration, and calcification were normalized by the content of protein and expressed in $\mu$ mol $\mathrm{O}_{2}(\mathrm{mg} \text { protein })^{-1} \mathrm{~h}^{-1}$.

A fresh SSW batch was prepared daily, a few hours prior to the experiments, as described by DOE (1994). Salinity was adapted to 38.5 in order to be close to the Mediterranean seawater salinity. The composition of SSW is shown in Table 1; all chemicals used were reagent grade (Merck). The $\mathrm{Ca}^{2+}$ concentration of the normal and low- $\mathrm{Ca}^{2+} \mathrm{SSW}$ were, respectively, 11.40 and $2.85 \mathrm{mmol} \mathrm{kg} \mathrm{m}^{-1}$. The parameters of the dissolved inorganic carbon system are shown in Table 2; further information can be found in Gattuso et al. (1998).

Proteins were solubilized in $\mathrm{NaOH}(1 \mathrm{~N})$ at $90^{\circ} \mathrm{C}$ for 30 min. Samples were then neutralized with $\mathrm{HCl}(1 \mathrm{~N})$, and the total protein content was measured using the Bradford method (Bradford 1976) with the Coomassie protein assay re- 

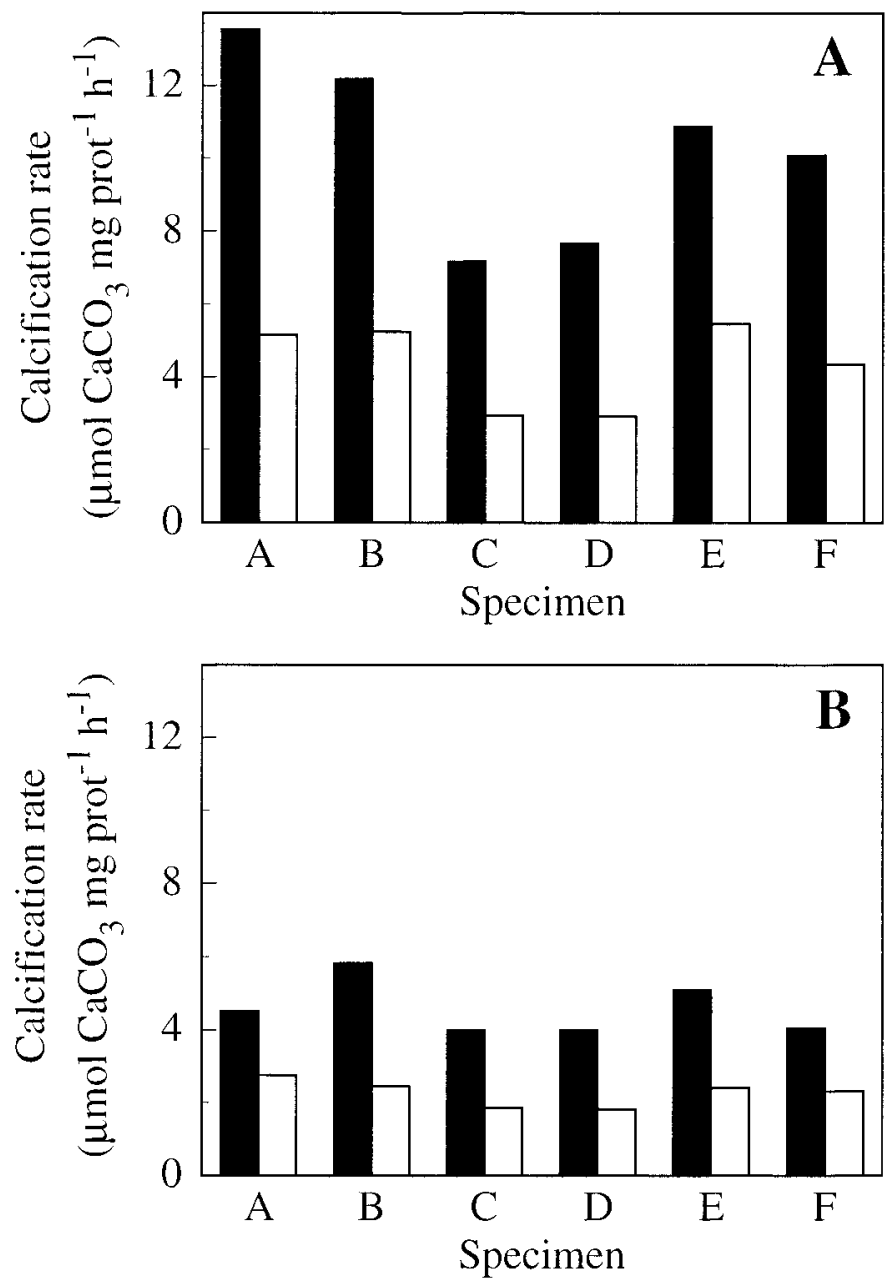

Fig. 1. Rate of calcification of the six specimens of S. pistillata investigated in the light (A) and in the dark (B), in standard (black bars) and low-calcium (white bars) synthetic seawater.

agent (Ref. 23200, Pierce). Optical density was read at 595 $\mathrm{nm}$ using a microplate reader (Multiskan ${ }^{\oplus}$ Bichromatic). Bovine gamma globulin (BGG) was used as a standard.

Statistical tests were performed with JMP 3.1.6 (SAS Institute, Cary, North Carolina). Results are expressed as mean \pm standard error of the mean (SE). $N$ is the sample size.

Results-The rates of calcification of colonies of S. pistillata in SSW with normal and low $\mathrm{Ca}^{2+}$ concentrations are shown in Fig. 1. They are significantly higher in the light than in the dark (paired $t$-test, $P<0.002)$ both in SSW $(10.3$ vs. $4.6 \mu \mathrm{mol} \mathrm{CaCO}_{3}[\mathrm{mg} \text { protein }]^{-1} \mathrm{~h}^{-1}$ ) and in low-Ca ${ }^{2+}$ SSW ( 4.3 vs. $2.3 \mu \mathrm{mol} \mathrm{CaCO}_{3}[\mathrm{mg} \text { protein }]^{-1} \mathrm{~h}^{-1}$ ). The average light: dark calcification ratio is 1.9-2.2. Calcification is 2-2.4 times lower in SSW with low $\mathrm{Ca}^{2+}$ concentration than SSW with normal $\mathrm{Ca}^{2+}$ concentration both in the light (4.3 vs. $10.3 \mu \mathrm{mol} \mathrm{CaCO}_{3}[\mathrm{mg} \text { protein }]^{-1} \mathrm{~h}^{-1}$ ) and in the dark (2.3 vs. $\left.4.6 \mu \mathrm{mol} \mathrm{CaCO}_{3}[\mathrm{mg} \text { protein }]^{-1} \mathrm{~h}^{-1}\right)$. These differences are statistically significant (paired $t$-test, $P<$ $0.001)$

The average net photosynthesis of S. pistillata was higher at low than at normal calcium concentration (10.2 vs. 7.5
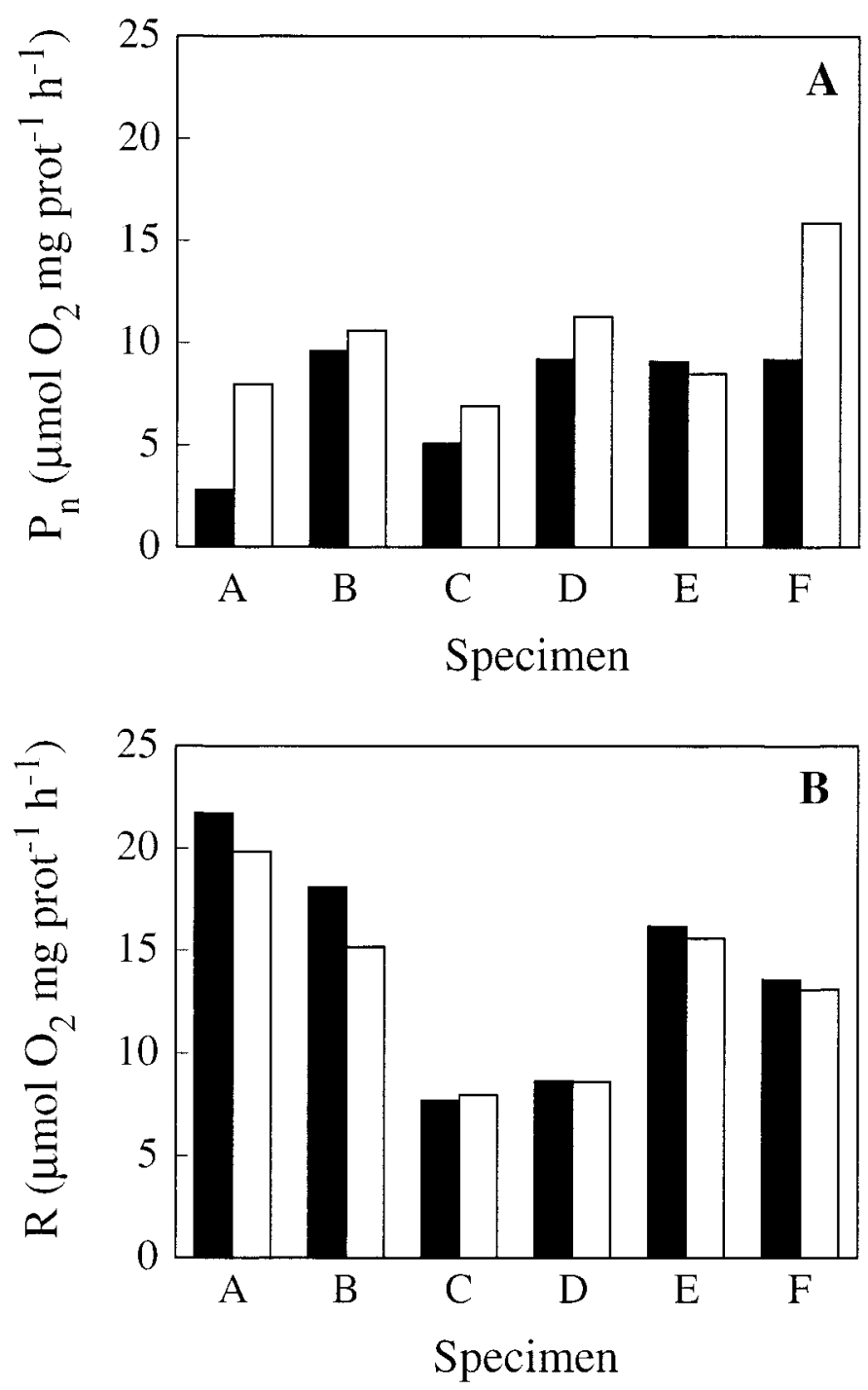

Fig. 2. Net photosynthetic rate (A) and absolute value of the respiration rate (B) of the six specimens of $S$. pistillata in standard (black bars) and low-calcium (white bars) synthetic seawater.

$\mu$ mol $\mathrm{O}_{2}$ [mg protein $]^{-1} \mathrm{~h}^{-1}$; Fig. 2A), but this difference was not statistically significant (paired $t$-test, $P=0.97$ ). The coral average respiration rate did not change significantly (paired $t$-test, $P=0.94$; Fig. 2B) in $\mathrm{Ca}^{2+}$-depleted SSW (13.4 $\mu \mathrm{mol} \mathrm{O}_{2}$ [mg protein $]^{-1} \mathrm{~h}^{-1}$ ) compared to standard SSW (14.3 $\mu \mathrm{mol} \mathrm{O}{ }_{2}$ [mg protein $\left.]^{-1} \mathrm{~h}^{-1}\right)$. The rates of net photosynthesis and respiration of the sea anemone A. viridis were identical in standard and low-Ca ${ }^{2+} \operatorname{SSW}\left(P_{n}: 81 \mu \mathrm{mol}\right.$ $\mathrm{O}_{2}[\mathrm{mg} \text { protein }]^{-1} \mathrm{~h}^{-1} ; R: 42 \mu \mathrm{mol} \mathrm{O}{ }_{2}[\mathrm{mg} \text { protein }]^{-1} \mathrm{~h}^{-1}$ ).

Discussion-Our data confirm previous results on the effect of light and calcium concentration on the rate of calcification of zooxanthellate scleractinian corals and provide new insights on the interaction between photosynthesis and calcification.

The calcification rate of the scleractinian coral S. pistillata is approximately twice higher in the light than in the dark, both in normal SSW and in calcium-depleted SSW. This 
light: dark calcification ratio is within the range of ratios reported in the literature for other species. In a recent compilation of 108 data collected under different environmental and biological conditions, and using various techniques, Gattuso et al. (1999) reported a large range of variation of this ratio (from negative values to 127 ) and found a median ratio of 3.0. It is possible that the irradiance level used in the present study did not saturate $\mathrm{CaCO}_{3}$ precipitation and that a higher ratio would have been found at a higher irradiance.

In agreement with previous results, the calcification rate is inhibited at low- $\mathrm{Ca}^{2+}$ concentrations. It is reduced by a factor of 2.0-2.4, depending on the level of irradiance, when the $\mathrm{Ca}^{2+}$ concentration is $25 \%$ of its normal value. Previous studies reported decreases of approximately 2 at such concentrations (Tambutté et al. 1996; Gattuso et al. 1998).

McConnaughey (1991, 1995) and McConnaughey and Whelan (1997) partly based the trans-calcification model, according to which calcification stimulates photosynthesis, on observations that the ratio of calcification versus net photosynthesis $\left(G / P_{n}\right)$ was close to 1 . They therefore inferred that $\mathrm{CO}_{2}$ released by calcification (Eq. 2) could sustain photosynthesis (Eq. 1). A survey of the literature recently confirmed that $G / P_{n}$ is higher than 1 in zooxanthellate scleractinian corals (median $=1.3$; Gattuso et al. 1999). Colonies of S. pistillata incubated in standard SSW exhibit an average ratio of 1.4. However, the amount of $\mathrm{CO}_{2}$ released per mole of $\mathrm{CaCO}_{3}$ precipitated varies according to the $\mathrm{CO}_{2}$ partial pressure of the medium (Frankignoulle et al. 1994). It is difficult to estimate this amount in scleractinian corals because there is no information on $p \mathrm{CO}_{2}$ in their coelenteron. Additionally, this amount is likely to vary according to irradiance. Using a tentative estimate of $0.6 \mathrm{~mol}$ of $\mathrm{CO}_{2}$ released per mole of $\mathrm{CaCO}_{3}$ precipitated (that is in standard seawater with $p \mathrm{CO}_{2}=350 \mu \mathrm{atm}$ ), Gattuso et al. (1999) estimated that calcification could supply, on average, $78 \%$ of the inorganic carbon required for zooxanthellar photosynthesis (84\% in the present study). This is a potential supply that had not been investigated so far.

We tackled this question by comparing net photosynthesis obtained when calcification proceeds unabated and under partially inhibited calcification, obtained in low-calcium seawater. Net photosynthesis should be inhibited under a low calcification rate if the trans-calcification model is correct. A fundamental prerequisite to the use of this approach is that low- $\mathrm{Ca}^{2+}$ seawater must have no significant effect on the rate of photosynthesis, irrespective of the calcification rate. This condition is impossible to assess in corals, where photosynthesis and calcification occur simultaneously and cannot be uncoupled in a natural way but was confirmed in another anthozoan, the noncalcifying zooxanthellate sea anemone A. viridis. Our results demonstrate that net photosynthesis of $S$. pistillata is not significantly affected when the rate of calcification is $58 \%$ of the normal rate of calcification (and the $G / P_{n}$ ratio is as low as 0.4 ) and can potentially supply only $24 \%$ of the photosynthetic inorganic carbon requirements. This is a strong argument suggesting that $\mathrm{CO}_{2}$ released by calcification is not a significant source of inorganic carbon for zooxanthellar photosynthesis in this species.

This result is not in agreement with some previous data that seem to support the trans-calcification model. Decreased calcium concentration inhibits photosynthesis in some organisms (reviewed in McConnaughey 1994). Al-Moghrabi et al. (1996) showed that the inhibition of calcification (by the removal of external $\mathrm{Ca}^{2+}$ or by adding $\mathrm{Ca}^{2+}$-channel inhibitors) induces a decrease of net photosynthesis in the scleractinian coral Galaxea fascicularis. The same result was obtained with foraminifera (Kuile ter et al. 1989), coccolithophorids (Brownlee et al. 1994), and calcareous algae (McConnaughey and Falk 1991). In contrast, and in agreement with our result, Yamashiro (1995) demonstrated that 1hydroxyethylidene-1, 1-bisphosphonic acid (HEBP), a specific inhibitor of mineral deposition, inhibits calcification of the scleractinian coral S. pistillata without any effect on the rate of photosynthesis. Similarly, an inhibitor of protein synthesis decrease coral calcification without disturbing photosynthesis (Allemand et al. 1998).

Several reasons can explain these discrepancies. First, the interaction between calcification and photosynthesis in various taxonomic groups is still poorly known and there is no integrative theory across taxa. It is possible that significant differences exist in evolutionarily distant taxa such as calcareous algae, foraminifera, coccolithophorids, and corals. Second, Al-Moghrabi et al. (1996) used a calcium concentration much lower than the one used in the present study $\left(0.2\right.$ vs. $\left.2.85 \mathrm{mmol} \mathrm{kg}{ }^{-1}\right)$. Calcium plays a major role in cell signaling (Carafoli and Penniston 1985); it is possible that very low concentration, in addition to inhibiting calcification, induces other physiological responses that might lead to decreased net photosynthesis. Third, we tentatively suggest that differences in the inorganic carbon system of the artificial seawater batches might partly explain these discrepancies. There is presently little information on the response of photosynthesis to elevated $p \mathrm{CO}_{2}$. It is possible that net photosynthesis is inhibited for reasons other than a low calcification rate, for example if the $\mathrm{Ca}^{2+}$-depleted seawater batches have a consistently lower $p \mathrm{CO}_{2}$.

We conclude (1) that the use of synthetic seawater with varying $\mathrm{Ca}^{2+}$ concentrations, controlled with respect to the dissolved inorganic system, is a powerful tool to decouple photosynthesis and calcification and investigate the interaction between both processes, (2) that photosynthesis is not affected by low- $\mathrm{Ca}^{2+}$ concentrations in a zooxanthellate sea anemone, and (3) that calcification does not stimulate photosynthesis in the zooxanthellate scleractinian coral S. pistillata. These results support the models of interaction that involve stimulation of calcification by photosynthesis but do not invalidate the trans-calcification model. They merely disagree with one aspect of this model (the coupling of photosynthesis and calcification). Other aspects of this model, such as the transport mechanisms of inorganic carbon, $\mathrm{Ca}^{2+}$ and $\mathrm{H}^{+}$, were not addressed by our experiments.

\section{J.-P. Gattuso, S. Reynaud-Vaganay, P. Furla, S. Romaine-Lioud, and J. Jaubert}

Observatoire Océanologique Européen,

Centre Scientifique de Monaco,

Avenue Saint-Martin,

MC-98000 Monaco, Principality of Monaco 


\section{Bourge and M. Frankignoulle}

Université de Liège,

Mécanique des Fluides Géophysiques,

Unité d'Océanographie Chimique (B5),

B-4000 Sart Tilman, Belgium

\section{References}

Allemand, D., P. Furla, and S. Bénazet-Tambutté. 1998. Mechanisms of carbon acquisition for endosymbiont photosynthesis in Anthozoa. Can. J. Bot. 76: 925-941.

Al-Moghrabi, S., C. Goiran, D. Allemand, N. Speziale, and J. JAUBERT. 1996. Inorganic carbon uptake for photosynthesis by the symbiotic coral-dinoflagellate association. 2. Mechanisms for bicarbonate uptake. J. Exp. Mar. Biol. Ecol. 199: 227-248.

BARNes, D. J., AND B. E. ChalKER. 1990. Calcification and photosynthesis in reef-building corals and algae, p. 109-131. In Z. Dubinsky [ed.], Coral reefs. Elsevier.

Bénazet-Tambutté, S., D. Allemand, ANd J. Jaubert. 1996. Inorganic carbon supply to symbiont photosynthesis of the sea anemone, Anemonia viridis: role of the oral epithelial layers. Symbiosis 20: 199-217.

BRADFORD, M. M. 1976. A rapid and sensitive method for the quantitation of microgram quantities of protein utilizing the principle of protein dye binding. Anal. Biochem. 72: 248-254.

Brownlee, C., N. Nimer, L. F. Dong, and M. J. Merrett. 1994. Cellular regulation during calcification in Emiliana huxleyi, p. 133-148. In J. C. Green and B. S. C. Leadbeater [eds.], The haptophyte algae. Clarendon Press.

Carafoli, E., And J. T. Penniston. 1985. The calcium signal. Sci. Am. 253: 50-58.

CARlon, D. B. 1996. Calcification rates in corals. Science 274: 117.

DOE. 1994. Handbook of methods for the analysis of the various parameters of the carbon dioxide system in sea water. ORNL/ CDIAC-74.

Frankignoulle, M., C. CAnon, AND J.-P. Gattuso. 1994. Marine calcification as a source of carbon dioxide-positive feedback of increasing atmospheric $\mathrm{CO}_{2}$. Limnol. Oceanogr. 39: 458462.

Gattuso, J.-P., D. Allemand, And M. Frankignoulle. 1999. Photosynthesis and calcification at cellular, organismal and community levels in coral reefs: a review of interactions and control by carbonate chemistry. Am. Zool. 39: 160-183.

, M. Frankignoulle, I. Bourge, S. Romaine, and R. W. BUDDEMEIER. 1998. Effect of calcium carbonate saturation of seawater on coral calcification. Global Planet. Change 18: 3746.

M. Pichon, B. Delesalle, And M. Frankignoulle. 1993.
Community metabolism and air-sea $\mathrm{CO}_{2}$ fluxes in a coral reef ecosystem (Moorea, French Polynesia). Mar. Ecol. Prog. Ser. 96: $259-267$.

Goreau, T. F. 1959. The physiology of skeleton formation in corals. I. A method for measuring the rate of calcium deposition by corals under different conditions. Biol. Bull. 116: 59-75.

- AND N. I. GoREAU. 1959. The physiology of skeleton formation in corals. II. Calcium deposition by hermatypic corals under various conditions in the reef. Biol. Bull. 117: 239-250.

Goreau, T. J., N. I. Goreau, R. K. Trench, and R. L. Hayes. 1996. Calcification rates in corals. Science 274: 117.

Kuile ter, B. H., J. ERez, And E. Padan. 1989. Competition for inorganic carbon between photosynthesis and calcification in the symbiont-bearing foraminifer Amphistegina lobifera. Mar. Biol. 103: 253-259.

MARShall, A. T. 1996. Calcification in hermatypic and ahermatypic corals. Science 271: 637-639.

McConnaughey, T. 1991. Calcification in Chara corallina: $\mathrm{CO}_{2}$ hydroxylation generates protons for bicarbonate assimilation. Limnol. Oceanogr. 36: 619-628.

. 1994. Calcification, photosynthesis, and global carbon cycles. Bull. Inst. Océanogr., Monaco nº́c. spéc. 13: 137-161.

. 1995. Ion transport and the generation of biomineral supersaturation. Bull. Inst. Océanogr., Monaco n spéc. 14: 1-18. , AND R. H. FALK. 1991. Calcium-proton exchange during algal calcification. Biol. Bull. 180: 185-195.

, AND J. F. Whelan. 1997. Calcification generates protons for nutrient and bicarbonate uptake. Earth Sci. Rev. 42: 95117.

Smith, S. V., AND G. S. Key. 1975. Carbon dioxide and metabolism in marine environments. Limnol. Oceanogr. 20: 493-495.

Tambutté, É., D. Allemand, E. Mueller, And J. Jaubert. 1996. A compartmental approach to the mechanism of calcification in hermatypic corals. J. Exp. Biol. 199: 1029-1041.

YAMASHIRO, H. 1995. The effects of HEBP, an inhibitor of mineral deposition, upon photosynthesis and calcification in the scleractinian coral, Stylophora pistillata. J. Exp. Mar. Biol. Ecol. 191: $57-63$.

Received: 7 May 1999 Accepted: 20 August 1999 Amended: 10 September 1999

\footnotetext{
${ }^{1}$ Observatoire Océanologique, ESA 7076 CNRS-UPMC, B.P. 28, F-06234 Villefranche-sur-mer Cedex, France (gattuso@obs-vlfr.fr).

Acknowledgments

Her coauthors dedicate this paper to the memory of Samantha Romaine-Lioud; she is sorely missed. Thanks are due to D. Allemand, T. McConnaughey, and S. V. Smith for comments on a draft version of this paper. M.F. is an FNRS (Belgium) research associate.
} 